MARCIN D. BUGDOL, Ph.D. ${ }^{1}$

(Corresponding author)

E-mail: marcin.bugdol@polsı.pl

PAWEL BADURA, Ph.D. ${ }^{1}$

E-mail: pawel.badura@polsl.pl

JAN JUSZCZYK, Ph.D. ${ }^{1}$

E-mail: jan.juszczyk@polsl.pl

WOJCIECH WIECLAWEK, Ph.D. ${ }^{1}$

E-mail: wojciech.wieclawek@polsl.pl

MARIA J. BIENKOWSKA, Ph.D. Student ${ }^{1}$

E-mail: maria.bienkowska@polsl.pl.

${ }^{1}$ Faculty of Biomedical Engineering,

Silesian University of Technology

Charlesa de Gaulle'a 66, 41-800 Zabrze, Poland
Intelligent Transport Systems (ITS)

Original Scientific Paper

Submitted: 27 Jan. 2017

Accepted: 11 Oct. 2017

\title{
SYSTEM FOR DETECTING VEHICLE FEATURES FROM LOW QUALITY DATA
}

\begin{abstract}
The paper presents a system that recognizes the make, colour and type of the vehicle. The classification has been performed using low quality data from real-traffic measurement devices. For detecting vehicles' specific features three methods have been developed. They employ several image and signal recognition techniques, e.g. Mamdani Fuzzy Inference System for colour recognition or Scale Invariant Features Transform for make identification. The obtained results are very promising, especially because only on-site equipment, not dedicated for such application, has been employed. In case of car type, the proposed system has better performance than commonly used inductive loops. Extensive information about the vehicle can be used in many fields of Intelligent Transport Systems, especially for traffic supervision.
\end{abstract}

\section{KEY WORDS}

vehicle type detection; vehicle make detection; vehicle colour detection; real traffic data;

\section{INTRODUCTION}

Every year the intensity of road traffic is constantly growing along with the increasing number of offences and traffic accidents. The services responsible for maintaining road order and safety require assistance in the form of automatic vehicle detection. With such dense traffic stream, the information about the car license plate only is usually insufficient, despite the popularity of such systems [1, 2]. An example is the Weighting In Motion (WIM) system, where relevant services are patrolling the route at a short distance from the measurement point. Obtaining data about the vehicle colour, make and category is crucial for a fast intervention and preventing damages to road infrastructure.
Many systems for visual analysis of car appearance have been proposed recently. Most of them are focused on recognizing only one of the mentioned features $[3,4,5]$. On the other hand more complex expert systems, designed to provide comprehensive information about the vehicle, have also been presented [6, $7,8]$.

Vehicle type recognition is usually performed on the basis of registered images $[9,10]$. Such solutions are computationally demanding, which implies a need to install more efficient and more expensive hardware on the monitoring site. A different approach, most common in practical applications, is vehicle category detection using inductive loops and recognizing the car type on the basis of the number of axes using proper algorithms [11, 12]. Inductive loops have to be installed in the road pavement and periodically serviced causing traffic jams. Most of the make recognition systems employ feature extraction and classification methods.

Commonly used feature extraction algorithms are: methods based on contour information [13], Canny edge detector [14], square mapped gradients [15], Curvelet Transform [16], Speeded-Up Robust Features (SURF) [6, 3] and Scale Invariant Feature Transform (SIFT) $[6,17]$. For classification purposes Support Vector Machines - SVM [16, 18], Bayesian methods [4, 19] or neural networks [20] are the most popular tools. There are, however, some limitations of the presented systems. The first one concerns the image quality. The authors of [4] used pictures of cars parked near the camera. Another problem is a small number of vehicle models in the database. In [6] a database of 17 different models has been used while the system presented by [21] recognizes among only 10 makes and models. 
Solutions for vehicle colour recognition differ in the colour space that is analyzed and the processing algorithm. In [22] a two-step process has been developed. First, the background is removed using the foreground mask. Then, the colour is recognized by a SVM classifier with a two-layer structure. The same classifier (SVM) is used by [23] for recognizing among five colours in HSV colour space (Hue, Saturation, Value), whereas [24] concentrated on HSI (Hue, Saturation, Intensity) colour space. A more complex approach is presented by [25], where the Grid Kernel has been proposed.

The aim of this study was to design a system for automatic detection of vehicle specific features (type, make and colour) from low quality data for real-time traffic supervision. Since the registered images and signals have been acquired using different measurement devices, various methods for detecting each feature have been employed. The colour recognition approach is based on a fuzzy system, which is able to distinguish 10 colours. The make classification employs the SIFT method for feature extraction with no limit for the number of classes. The vehicle type recognition has been performed on one dimensional data yielding a more robust algorithm than image-based approaches.

This paper is an extension of [26] and [27], where the preliminary studies results for vehicle make and colour detection have been presented. In this study the image processing stage for reliable car brand pattern detection has been revised and improved mainly by the redevelopment of the car brand segmentation and classification algorithms. The brand segmentation involves vehicle lights extraction along with texture analysis. The classifier relies mainly on the information about the image compatibility with reference patterns. Moreover, a more comprehensive evaluation and analysis have been performed using car images including 46 car makes and 10 colours. Special attention has been paid to the influence of the value of the SIFT distance ratio $r_{d}$ value on recognition efficiency. The vehicle type detection on the basis of one-dimensional signal registered with laser distance meter is also a novel part of the presented work.

The paper is organized as follows. Section 2 presents the measurement system and the data set used in the research. The algorithms for detecting vehicle type, colour and make are described in Section 3. Section 4 contains the results and Section 5 draws the conclusion.

\section{DATA}

The detection of vehicle specific features has been performed on the basis of data registered on WIM stations, which have been equipped with the following devices:
- Noptel CM3-30 laser distance meter for acquiring vehicle height (sampling frequency $1 \mathrm{kHz}$ ),

- colour camera with image resolution of $640 \times 480$ for registering colour images of vehicles,

- camera, a part of the Automatic Number Plate Recognition (ANPR) system, taking pictures of vehicle fronts with the resolution of $752 \times 480$.

All devices have been mounted above the road line as shown in Figure 1. The image registration is triggered when a vehicle passes the inductive loops embedded in the road surface. The laser sensor starts recording when the measured vehicle height exceeds the predefined threshold $(50 \mathrm{~cm})$ and stops when the height drops to zero.

More than 2,000 objects of each data type have been recorded. Figure 2 presents an exemplary set of registered data which includes the colour camera picture (Figure 2a), the ANPR camera picture (Figure 2b) and the vehicle height vector, consisting of height values registered using the laser distance meter with the time step of $1 \mathrm{~ms}$ (Figure $2 \mathrm{c}$ ).

Preliminary studies have indicated that the colour camera resolution is too low to detect the car manufacturer, and the camera of ANPR system does not provide colour images. Therefore, two cameras had to be employed.
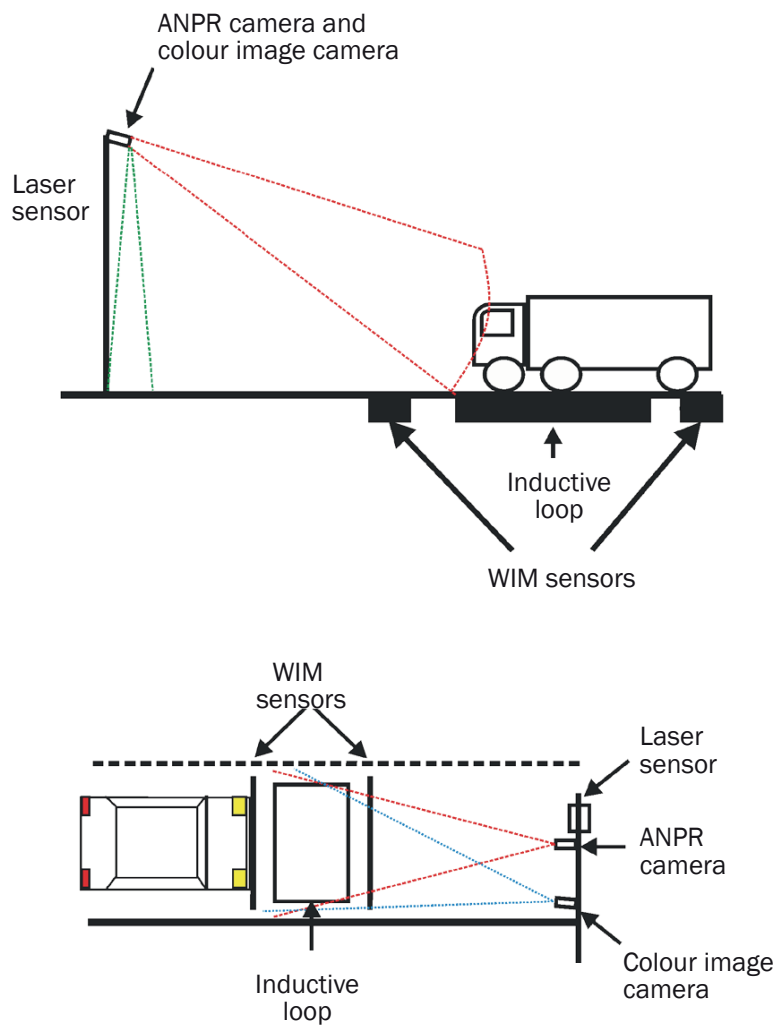

Figure 1 - Configuration of data acquisition devices 


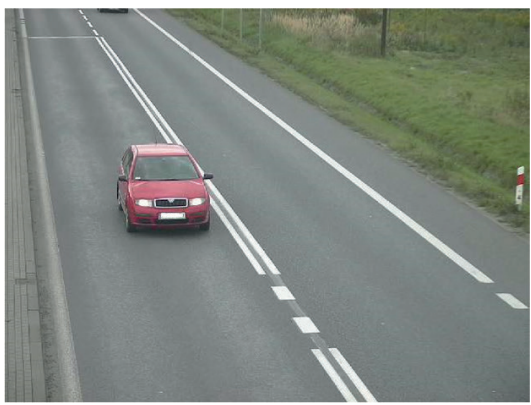

a) Image from the colour camera for vehicle colour detection

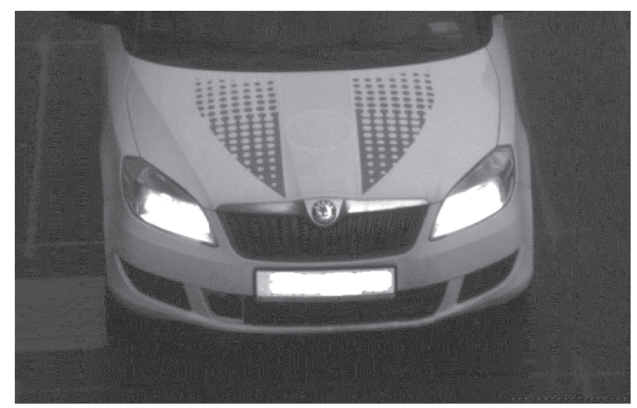

b) Image from the ANPR camera for make detection

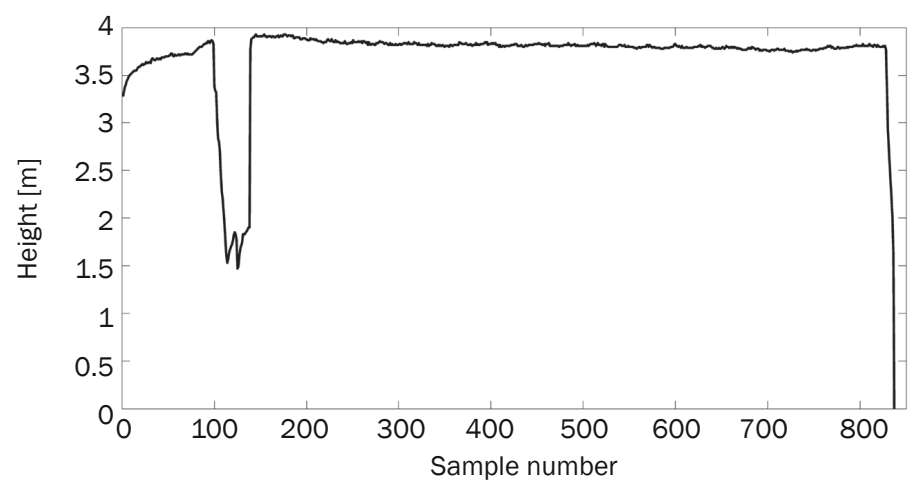

c) Vehicle height vector registered with the laser distance meter

Figure 2 - Data examples

\section{METHODS}

\subsection{Vehicle type detection}

Vehicle category detection has been performed on the basis of the European Specification COST 323 [11], which defines eight categories of vehicles: 1 - car and light trailer (gross-weight<3.5t), 2 - two-axle rigid lorry, 3 - more than two-axle rigid lorry, 4 - tractor with semi-trailer supported by single or tandem axles, 5 tractor with semi-trailer supported by tridem axles, 6 - lorry with trailer, 7 - bus, 8 - other vehicles. Since categories 2 and 3 are distinguishable only on the basis of axle number and this parameter cannot be measured with a distance meter, these two categories have been joined into one (denoted in paper as 23). The same applies to categories 4 and 5 , which have built category 45.

The laser distance meter provides a vector of vehicle height $V H$ that represents the vehicle contour. Based on the registered vehicle contour the following vehicle features have been extracted:

- the mean, maximum and variance of the vehicle height,

- vehicle length,

- the existence and position of the contour indentation, representing the indentation between the tractor and its semi-trailer (category 45 ) or between lorry and trailer (category 6).
Figure 3 presents a graphical illustration of the evaluated parameters.

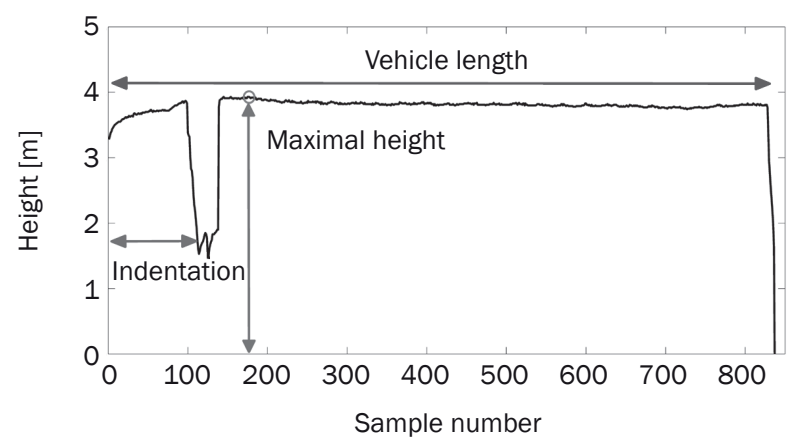

Figure 3 - An illustration of vehicle contour features

Vehicle height $V H_{m}$ is determined by:

$V H_{m}=\max (V H)$

The variance of vehicle height $\left(s_{V H}^{2}\right)$ has been computed in order to distinguish between lorries and buses. The idea, which was behind the calculation of the variance, resulted from the observation that the height of the bus roof varies to a very small extent, in contrast to the truck where the cabin and trailer have different heights. In addition, there is a gap between the cabin and the trailer, which also increases the value of the variance. The first and last $10 \%$ of samples of the height vector are not included in the variance 
calculation, because they contain information about the front and the rear of the vehicle, where the height is changing rapidly, which greatly affects the resulting variance. The number of excluded samples has been chosen empirically.

The sampling frequency of height measurement is given (here $f=1,000 \mathrm{~Hz}$ ) and the distance $D(f, v)$ covered by the vehicle between each measurement can be calculated as:

$$
D(f, v)=3.6^{-1} \cdot 10^{-3} f^{-1} \cdot v
$$

where: $v$ - is the vehicle velocity in $\mathrm{km} / \mathrm{h}$.

The vehicle velocity has been provided by the inductive loop, since it has been available on the WIM site. In the final solution two laser distance meters can estimate the velocity as well.

Vehicle length is estimated using the position of the last non-zero value in the vehicle height vector $I E$ (Index End). Then, the vehicle length - $L$ (in metres) is obtained from the formula:

$L=D(f, v) \cdot I E$

For categories 45 and 6 the indentation between the first and the second unit of the vehicle has been calculated. For category 45 it is the end of the cabin and for category 6 it is the gap between the lorry and the trailer. The vehicle contour signal has been filtered in order to reduce the noise. The indentation position has been determined by the index of the first value that is lower than the half of the vehicle height (II Index Indentation):

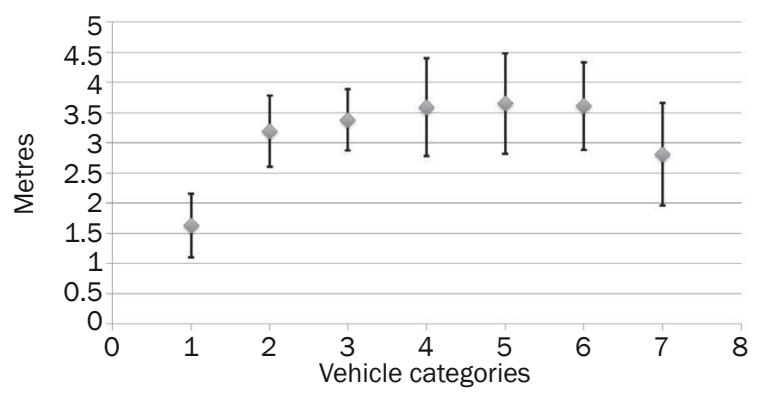

a) Height
$I I=\min (I):\left\{V H(I)<0.5 \cdot V H_{m}\right\}$

The value of II has been selected empirically. In order to suppress the distortion, the middle value between the maximum vehicle height and the ground has been chosen. This feature distinguishes between categories 45 and 6. For categories 1, 23 and 7, the value of $I I$ equals $L$.

\section{Category classification algorithm}

Sample data have been analyzed and the distribution of the extracted shape features values has been calculated. The results of height, length and position of the $1^{\text {st }}$ unit are shown in Figure 4. Central points represent mean features values and the whiskers mark the double standard deviation.

On the basis of the analysis of the obtained results, a set of rules for classification purposes has been developed (Table 1).

Table 1 - Vehicle category classification rules

\begin{tabular}{|c|c|c|c|c||}
\hline \hline Category & $V H_{m}[\mathrm{~m}]$ & $L[\mathrm{~m}]$ & $I I[\mathrm{~m}]$ & $s_{V H}^{2}$ \\
\hline \hline 1 & $<2.5$ & $<6$ & - & - \\
\hline 23 & $>2.5$ & $6.0-12.0$ & - & $>75$ \\
\hline 45 & $>2.5$ & $>12.0$ & $<3.5$ & $>75$ \\
\hline 6 & $>2.5$ & $>12.0$ & $>3.5$ & $>75$ \\
\hline 7 & $>2.0$ & $6.0-12.0$ & - & $<75$ \\
\hline
\end{tabular}

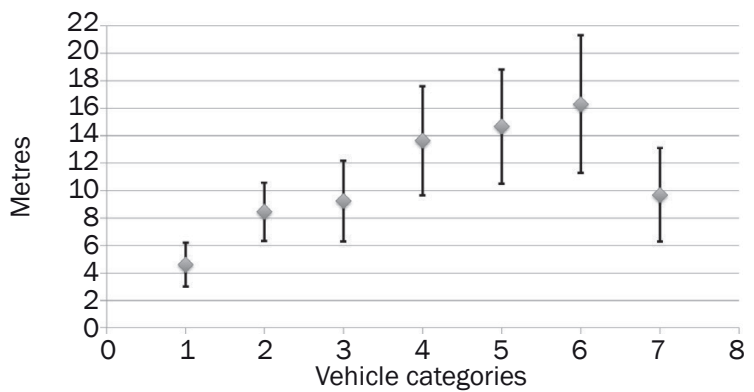

b) Length

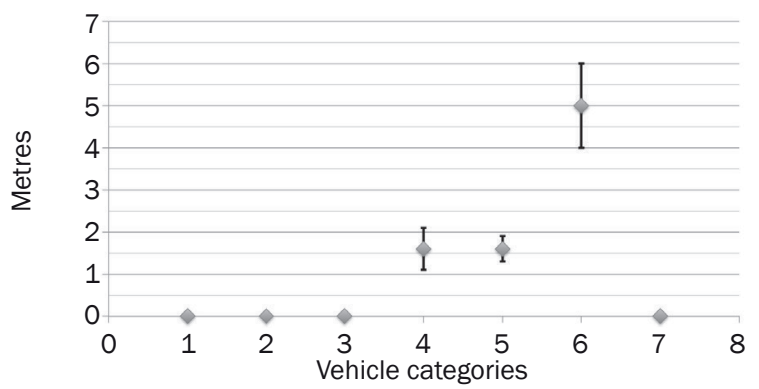

c) Indentation

Figure 4 - Distributions of shape features for each category 


\subsection{Vehicle colour detection}

The vehicle's colour should be a member of a closed colour group, consisting of ten hues. These are: white, grey, black, red, brown, orange, yellow, green, blue and purple. The colour detection algorithm has been created on the basis of the regulation of the Polish Ministry of Transport for car colours.

The proposed methodology contains three stages: car segmentation, region of interest (ROI) detection and colour recognition.

\section{Segmentation}

The car segmentation procedure detects the vehicle foreground from all cars visible in the image (Figure 5a). To solve this problem a grey scale image is analysed. The procedure is based on the car shadow detection. As a shadow the darkest pixels (pixels with the lowest intensity value) in the image are considered (Figure 5b). Since these pixels are located under the car, their shape and position are independent on light conditions, which has been checked on pictures taken at different times of the day. What is more, the horizontal part of the shadow is sufficient to prevent mistakes for long vehicles.

Very often the number of areas that satisfy the mentioned condition, is greater than one. Therefore, a correction is required. It relies on a selection of the largest darkest area located in the lower left corner of the image (extreme left-hand lane). A preliminary study confirms that in more than $98 \%$ of the cases the front shadow of the car is obtained. What is more, the width $\mathrm{w}$ of the shadow corresponds to the car width. (Figure 5c). On the basis of that knowledge, a rectangular region of interest is built (Figure $5 d$ ). Since the typical car aspect ratio (i.e. width: height) equals 4:3, the lengths of the rectangle sides are height $=\frac{\text { width }}{3}$. This rule also works correctly for vans and trucks, since the region contains a significant part of the coloured vehicle elements.

\section{ROI detection}

The car segmentation procedure is followed by the extraction of the region of interest (ROI) (Figure 6a). On its basis an auxiliary image (Figure $6 b$ ) is created. It presents stripes with the standard deviation of image hue computed for each row of Figure 6a. Next, the stripe with the lowest standard deviation value is selected. It forms the area/zone that reflects the car colour (Figure 6c).

\section{Colour recognition}

The procedure of colour recognition works in the HSV colour space. These three components are the input data for Mamdani Fuzzy Inference System (MFIS). The fuzzy system has been described in details in [27].

\subsection{Vehicle make detection}

The automatic make recognition system has been developed for the detection of specific car makes based on low-contrast images of car fronts (Figure 7a). The algorithm consists of four stages: car brand segmentation, feature extraction, pattern matching and classification.

\section{Car brand segmentation}

Car brand segmentation begins with the license plate detection stage. The detection of the lights leads to the extraction of the ROI in-between and below

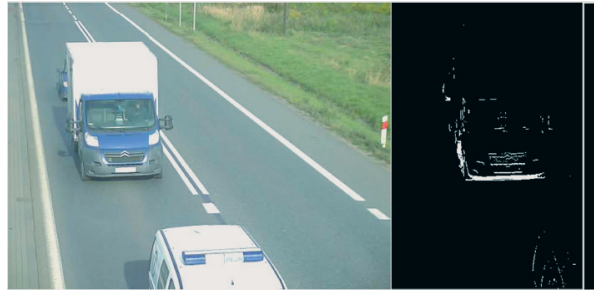

a) b)

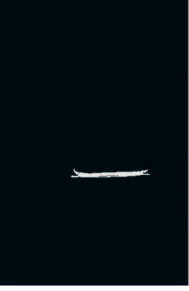

C)

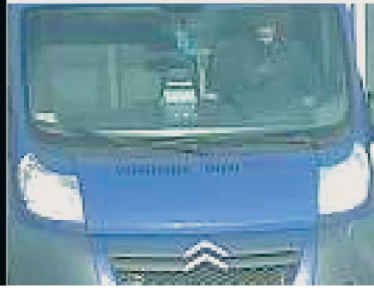

d)

Figure 5 - Car segmentation stages

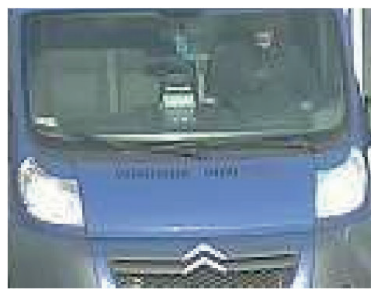

a)

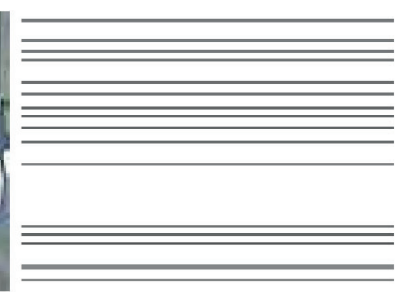

b)

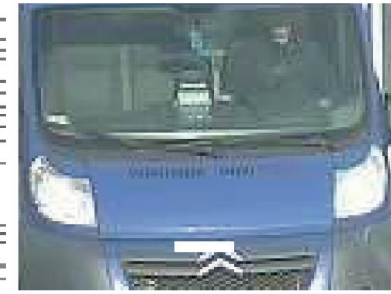

c)

Figure 6 - Region of interest (ROI) detection stages 


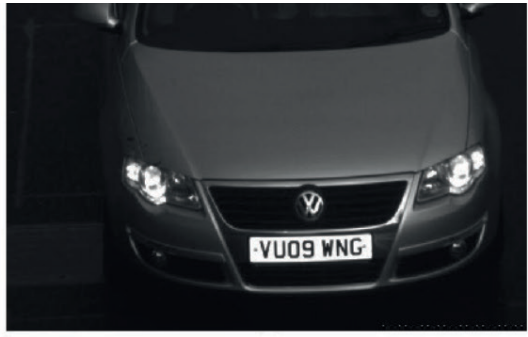

a)

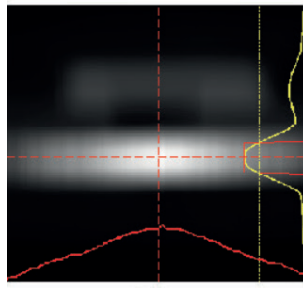

d)

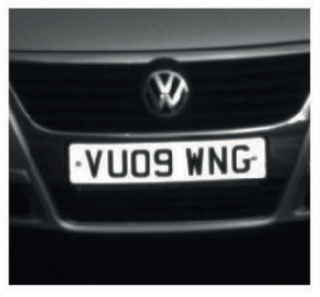

b)

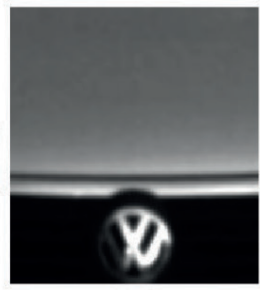

f)

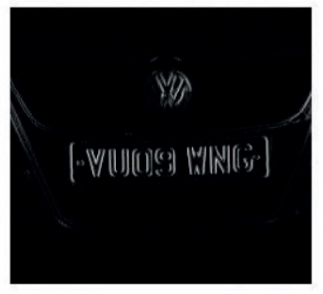

c)

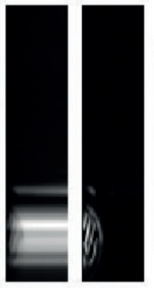

g) h)

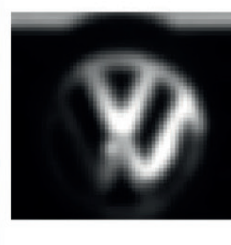

i)

Figure 7 - Image pre-processing stages

a) original image; b) license plate ROI; c), d), e) selected illustrations of license plate detection stages; f) car brand ROI; g), h), i) selected illustrations of car brand detection stages

(Figure $7 b$ ). The ROI is analyzed in terms of the texture features in order to detect the plate region (Figure 7c-e). The image is then rotated to position the plate parallel to the image horizontal axis. A region above the license plate is extracted for the car make symbol detection (Figure 7f).

A few assumptions have been made: (1) the brand is supposed to be located on the ROI vertical axis of symmetry; (2) it should feature high spatial frequency components; (3) due to its symmetry the extraction relies mainly on horizontal gradient features (Figures $7 \mathrm{~g}$ and $7 \mathrm{~h}$ ). As a result, a small rectangle including the car brand is extracted and passed to the recognition stage (Figure 7i).

\section{Feature extraction}

For feature extraction the Scale Invariant Feature Transform (SIFT) has been used [28, 29]. It is based on key points - extrema within the image scale space [30, 31]. Each extracted key point is represented by its location, scale, orientation and a vector of textural descriptors. The key issue here is to choose the proper image/ $\mathrm{ROI}$ as an input of the SIFT analysis. Due to the image character, contrast and compression method (JPEG), the car brand ROI as described above has been found as the best choice for the analysis (Figure 8). Moreover, the ROI is subjected to a slight Gaussian filtering, contrast enhancement and resampling, to normalize the length of the longer ROI side at 128 pixels. Such an image generates ca. 10-60 key points.

\section{Pattern matching}

Lowe's SIFT pattern matching relies on fitting the descriptor vectors by means of their Euclidean distance, all performed for each pair of key points. If the

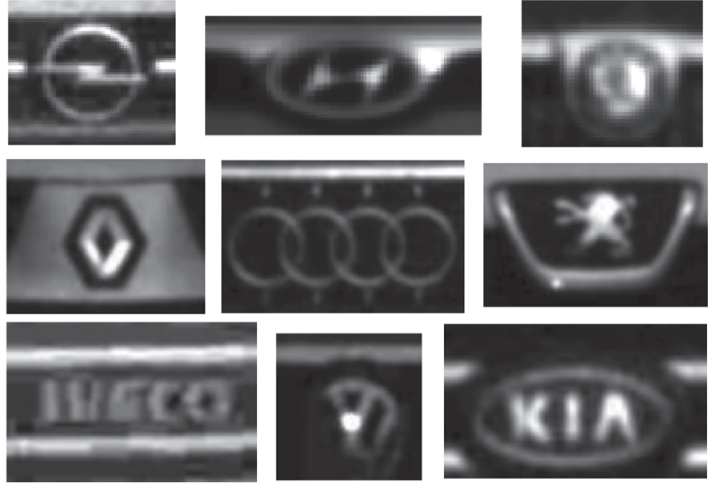

Figure 8 - Sample car brand ROI images

distance between two points from various patterns is significantly small, they can be considered as being matched. To make the matching process fully automatic, a comparison between the closest and the second-closest key point is performed. If the distance ratio is lower than constant $r_{d}$ value, then the match is approved.

Each extracted image is compared to reference patterns from the database, which consists of $N_{\mathrm{g}}$ groups (car makes) with $N_{p p b}$ patterns per brand. Some makes have various, significantly different symbols for their car models (e.g. Fiat or Dacia): each separate symbol constitutes a unique group. Therefore, $N_{\mathrm{g}}$ is generally slightly greater than the number of supported car makes. The process of reference patterns selection investigates their high ability to match samebrand samples and their low false positive susceptibility. Comparison of the sample with the reference 
database objects produces matching vector $\mathbf{M}$, containing numbers of key points shared with subsequent reference patterns.

\section{Classification}

At the classification stage vector $\mathbf{M}$ is examined, matching the sample under consideration via a multirule inference system:

1) A brand with the highest average number of matches within a group is chosen.

2) If the above rule produces no sole winner, the individual pattern with the highest number of matching key points induces the decision.

3) If there is still no unique decision, the top of the best matching reference patterns list is inspected to indicate the best represented brand.

4) Unsuccessful classification using all three above rules generates the decision "unrecognised".

\section{RESULTS}

All proposed methods have been implemented in Matlab R2012b and tested using the dataset presented in Section 2. Each test image has been assigned to one category, one colour and one make. Next, the percentage of correctly classified vehicles has been computed.

Car type detection results have been presented in Table 2. It can be noticed that the proposed method, employing laser distance meter, gives higher accuracy of detecting particular types than the algorithm that uses inductive loop as the measuring device. The difference between the overall accuracy is about 5\% and it is determined by the first category which includes the largest number of cases (cars of total gross weight $<3.5 \mathrm{t}$ ). The presented approach (in terms of the number of the distinguished vehicle types) does not provide as many data about the vehicle as inductive loops, yet it is comparable with image-based solutions while it has a far lower computational complexity and is insensitive to weather conditions.

Table 2 - Car category recognition results

\begin{tabular}{|c|c|c|c||}
\hline Category & No. of cases & $\begin{array}{c}\text { Correct } \\
\text { detection [\%] }\end{array}$ & $\begin{array}{c}\text { Loop correct } \\
\text { detection [\%] }\end{array}$ \\
\hline \hline 1 & 2,417 & 99.92 & 97.97 \\
\hline 23 & 106 & 82.08 & 65.09 \\
\hline 45 & 264 & 98.86 & 71.21 \\
\hline 6 & 31 & 83.87 & 51.61 \\
\hline 7 & 16 & 75.00 & 56.25 \\
\hline \hline Total & 2,834 & 98.84 & 93.51 \\
\hline
\end{tabular}

The colour recognition algorithm has been verified using a data set including 2,419 images. The database includes vehicles of different brands and types (passenger cars, vans, trucks and buses). The detailed results are presented in Table 3.

Table 3 - Car colour recognition results

\begin{tabular}{||c|c|c|c||}
\hline Colour & No. of cases & Correct [\%] & $\begin{array}{c}\text { Mostly } \\
\text { mistaken for }\end{array}$ \\
\hline \hline Brown & 5 & 40 & Grey \\
\hline White & 655 & 68.24 & Grey \\
\hline Grey & 825 & 61.33 & Blue \\
\hline Black & 67 & 0 & Blue \\
\hline Orange & 54 & 25.93 & Grey \\
\hline Yellow & 56 & 19.64 & Green \\
\hline Green & 98 & 38.78 & Blue \\
\hline Blue & 385 & 86.75 & Grey \\
\hline Purple & 46 & 78.26 & Grey \\
\hline Red & 228 & 60.53 & Grey \\
\hline \hline Total & 2,419 & 63.08 & \\
\hline
\end{tabular}

Values included in Table 3 refer to the total assessment of both stages: ROI detection and colour recognition. The error of ROI detection procedure very often arises from identifying the windscreen as the body of the car, whereas the correct performance of MFIS has been often disturbed by improper light exposure. Studies and numerical simulations led to the observation that methods of colour detection have to consider the light direction. Even local analysis, within homogeneous stripes, does not provide efficiency higher than $60 \%$. Moreover, the colour recognition procedure often yields a neighbour colour or a grey colour. The similarity is visible in pairs Grey-Blue, Black-Blue, Yellow-Green, Green-Blue (pairs are understood as real colour-recognized colour). Incorrectly detected colours are the significant components of the real or neighbour colours in the HSV colour palette, whereas the system reports grey colour when lighting conditions were poor or the analysed images were of very low quality.

Evaluation of the car segmentation procedure has been presented in [27] and reached 98\%. It has been proven that the segmentation efficiency is independent on the type (short or long vehicles), brands and even light conditions (sunny or cloudy day).

The obtained results are comparable with those presented in [23], where also an automatic classifier has been employed. However, in that paper the authors have verified the proposed methodology on the basis of the set of 500 images with higher quality and where the car colours were clear. In such conditions the efficiency of colour recognition has reached about $90 \%$. 
In this study the car make recognition approach has been evaluated using a set of 8,447 images containing 46 various car makes. Training images for pattern matching are taken from the entire data set. In each experiment, an automated procedure for selection of reference patterns per each brand is performed. It involves mutual matching between all pairs of images and selection of the most discriminant patterns in terms of both recognition sensitivity and specificity. First, the influence of two parameters has been investigated: the SIFT matching distance ratio $r_{d}$ $([0.25,0.95])$ and the number of patterns per brand in the reference database $N_{p p b}([3,10])$. In each trial a series of operations has been performed: (1) reference database generation by automated selection of $N_{p p b}$ reliable patterns (if a car make has not got enough samples to supply the reference database plus at least one test sample, it is excluded from the experiment); (2) examination of all remaining test samples by comparing with the reference database; (3) calculation of two efficiency measures, defined as follows:

- recognition efficiency $E_{r e c}$ :

$E_{\text {rec }}=\frac{N_{T P}}{N_{T P}+N_{F N}} \cdot 100 \%$

- total efficiency $E_{\text {tot }}$ :

$E_{\text {tot }}=\frac{N_{T P}}{N} \cdot 100 \%$

where $N$ is the total number of test samples, $N_{T P}$ and $N_{F N}$ are the numbers of true positive and false negative matches, respectively. $N=N_{T P}+N_{F N}+N_{U}$, with $N_{U}$ being the number of unrecognized cases. Figures $9 a$ and $9 b$ show charts of both efficiencies depending on $r_{d}$ and $N_{p p b}$.

The lower the $r_{d}$ value, the more reliable decisions (higher $E_{r e c}$ ) are obtained and more unclassified cases appear (higher $N_{U}$ and consequently lower $E_{t o t}$ ). The highest total efficiency exceeding $70 \%$ can be
Table 4 - System efficiency for specific car makes $\left(r_{d}=0.80, N_{p p b}=7\right)$

\begin{tabular}{||l|c|c|c|c|c|c||}
\hline \hline Make & $\begin{array}{c}E_{r e c} \\
{[\%]}\end{array}$ & $\begin{array}{c}E_{\text {tot }} \\
{[\%]}\end{array}$ & $N$ & $N_{T P}$ & $N_{F N}$ & $N_{U}$ \\
\hline \hline Seat & 84.8 & 84.8 & 112 & 95 & 17 & 0 \\
\hline Opel & 84.0 & 83.7 & 989 & 828 & 158 & 3 \\
\hline Suzuki & 82.1 & 82.1 & 78 & 64 & 14 & 0 \\
\hline Mercedes & 80.0 & 80.0 & 631 & 505 & 126 & 0 \\
\hline Ford & 76.4 & 76.1 & 476 & 362 & 112 & 2 \\
\hline Skoda & 74.5 & 74.2 & 730 & 542 & 186 & 2 \\
\hline Volvo & 72.9 & 72.9 & 96 & 70 & 26 & 0 \\
\hline Hyundai & 73.0 & 72.4 & 127 & 92 & 34 & 1 \\
\hline Chevrolet & 72.3 & 72.3 & 47 & 34 & 13 & 0 \\
\hline Kia & 72.1 & 72.1 & 111 & 80 & 31 & 0 \\
\hline Volkswagen & 71.3 & 71.2 & 1290 & 918 & 369 & 3 \\
\hline Renault & 71.4 & 71.1 & 768 & 546 & 219 & 3 \\
\hline Dacia & 68.6 & 68.6 & 35 & 24 & 11 & 0 \\
\hline Honda & 64.3 & 63.8 & 116 & 74 & 41 & 1 \\
\hline Peugeot & 63.8 & 63.6 & 379 & 241 & 137 & 1 \\
\hline Audi & 60.5 & 60.5 & 354 & 214 & 140 & 0 \\
\hline Toyota & 59.9 & 59.9 & 397 & 238 & 159 & 0 \\
\hline Iveco & 59.7 & 59.7 & 119 & 71 & 48 & 0 \\
\hline Citroën & 55.4 & 55.1 & 383 & 211 & 170 & 2 \\
\hline Fiat & 54.4 & 53.5 & 482 & 258 & 216 & 8 \\
\hline FSo & 50.0 & 50.0 & 6 & 3 & 3 & 0 \\
\hline Dodge & 50.0 & 50.0 & 2 & 1 & 1 & 0 \\
\hline Mitsubishi & 48.2 & 46.6 & 58 & 27 & 29 & 2 \\
\hline BMW & 46.2 & 46.2 & 119 & 55 & 64 & 0 \\
\hline Mazda & 44.9 & 44.9 & 69 & 31 & 38 & 0 \\
\hline Chrysler & 44.4 & 42.1 & 19 & 8 & 10 & 1 \\
\hline Lexus & 40.0 & 40.0 & 5 & 2 & 3 & 0 \\
\hline Nissan & 30.9 & 30.4 & 112 & 34 & 76 & 2 \\
\hline Daewoo & 28.6 & 28.6 & 21 & 6 & 15 & 0 \\
\hline Subaru & 20.0 & 20.0 & 5 & 1 & 4 & 0 \\
\hline Land Rover & 0.0 & 0.0 & 5 & 0 & 5 & 0 \\
\hline \hline
\end{tabular}

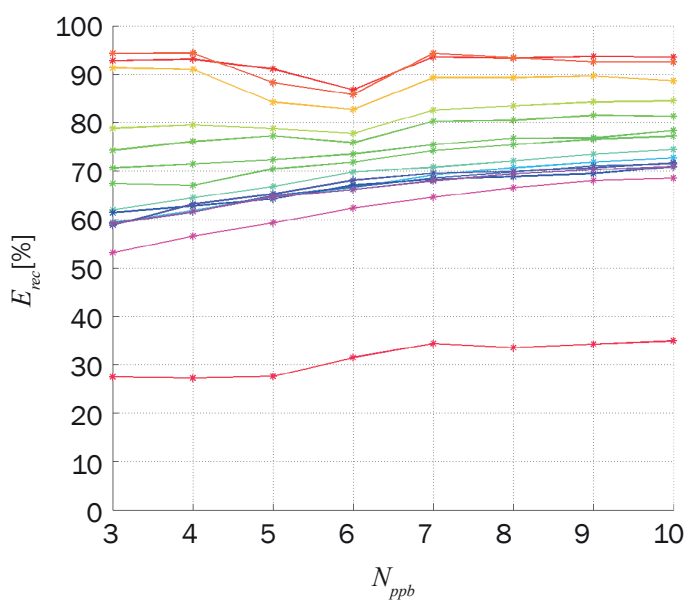

a) $E_{r e c}$

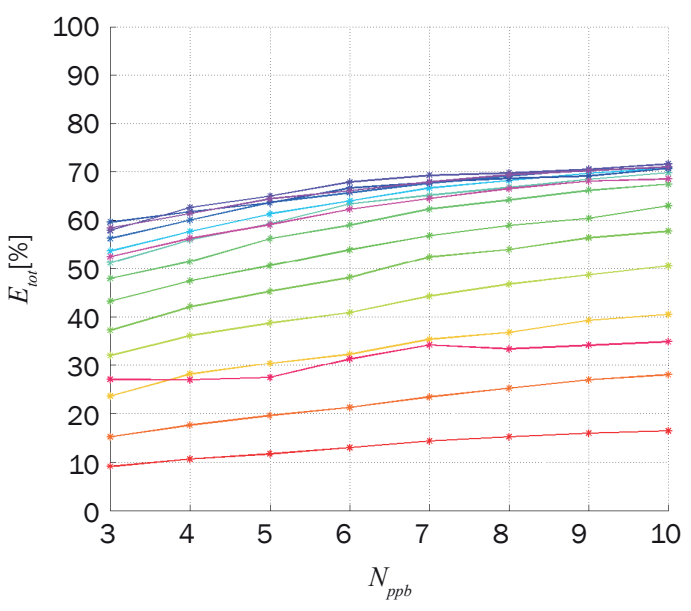

b) $E_{t o t}$

Figure 9 - Car make recognition efficiencies as functions of parameters $r_{d}$ and $N_{p p b}$ 
obtained for $r_{d} \in[0.65,0.80]$. On the other hand, $E_{t o t}$ shows a growing trend in the domain of the number of patterns per brand.

Finally, Table 4 presents the efficiency details for all car makes involved in the experiment with $r_{d}=0.80$ and $N_{p p b}=7$. Makes absent due to underrepresentation: Rover, Vauxhall, Lancia, Mini, Smart, Jeep, Infiniti, Tata, Cadillac, Alfa Romeo, Saab, Range Rover, Jaguar, Maserati, Isuzu.

All makes represented in Table 4 were captured on images. However, these images were not all captured by the camera. About 30\% of the total number of car front images were taken in very poor lighting condition and it was not possible to recognize the car brand even by a human.

The main advantages of the presented make recognition system lie (1) in its ability to handle low quality images, (2) in its flexibility in reference database extension and adaptation, and (3) in a large number of testing data. Some earlier studies report high efficiency (96\%) of make and model recognition [4] yet the dataset contains pictures of parked cars, taken from small distance (1.5-3 m). The requirement to cover a large number of car models present in real traffic has not been fulfilled in most of the presented approaches: [6] describe the 17-model recognition system with the 91.7\% accuracy; [21] show $62.53 \%$ accuracy with a database of only 10 car makes and models. The small amount of database samples is given in [32] as the reason of a $45 \%$ efficiency, yielded by their car brand recognition algorithm.

\section{CONCLUSION}

A system for detecting vehicle specific features has been presented. It utilizes real traffic low quality data to recognize the vehicle colour, make and type. Different methods have been proposed for each modality and the obtained results are very promising. In future works the system can be extended to provide more detailed information about the vehicle type i.e. semi-trailer type (box, tank etc.). The ROI detection for colour recognition module will be improved to detect more accurate coloured vehicle elements. Since the vehicle make recognition efficiency exceeds $70 \%$ in case of low quality images, the performance improvement might be expected after employing better suited data. It has been also planned to evaluate other pattern matching tools instead of SIFT.

\section{ACKNOWLEDGMENTS}

Authors would like to thank APM Pro Company, Bielsko-Biala, Poland, for valuable cooperation and providing data. This project was funded by the Polish Agency for Enterprise Development funds No. 54/ WDB/DPP/13. Publication supported by the Rector's
Grant in the field of research and development. Silesian University of Technology, Grant number 07/010/ RGJ17/0014.

MARCIN D. BUGDOL, dr inż. ${ }^{1}$

E-mail: marcin.bugdol@polsl.pl

PAWEL BADURA, dr inż. ${ }^{1}$

E-mail: pawel.badura@polsl.pl

JAN JUSZCZYK, dr inż. $1^{1}$

E-mail: jan.juszczyk@polsı.pl

WOJCIECH WIECLAWEK, dr inż. ${ }^{1}$

E-mail: wojciech.wieclawek@polsl.pl

MARIA J. BIENKOWSKA, mgr inż. ${ }^{1}$

E-mail: maria.bienkowska@polsı.pl

${ }^{1}$ Wydział Inżynierii Biomedycznej, Poliechnika Śląska

ul. Charlesa de Gaulle'a 66, 41-800 Zabrze, Polska

\section{SYSTEM DETEKCJI SZCZEGÓLNYCH CECH POJAZDU NA PODSTAWIE DANYCH NISKIEJ JAKOŚCI}

\section{STRESZCZENIE}

W artykule przedstawiono system rozpoznawania marki, typu oraz koloru pojazdu na podstawie danych niskiej jakości, pochodzących z urządzeń rejestrujących rzeczywisty ruch drogowy. W celu detekcji szczególnych cech pojazdów zaproponowano trzy metody, które wykorzystują kilka technik z zakresu przetwarzania sygnałów i obrazów, takich jak system wnioskowania rozmytego o strukturze Mamdaniego do rozpoznawania kolorów, czy skalo-niezmiennicze przekształcenie cech (ang. Scale-Invariant Feature Transform) do identyfikacji marki pojazdu. Uzyskane rezultaty są obiecujące, zwłaszcza, że skorzystano z urządzeń dostępnych na stacjach pomiarowych, które nie były dedykowane temu celowi. W przypadku typu pojazdu zaproponowane rozwiązanie charakteryzuje się lepszą dokładnością niż powszechnie wykorzystywane pętle indukcyjne. Wyczerpujące informacje o pojazdach mogą zostać wykorzystane w wielu dziedzinach z zakresu inteligentnych systemów transportowych, w szczególności do nadzoru ruchu drogowego.

\section{SŁOWA KLUCZOWE}

detekcja typu pojazdu; detekcja marki pojazdu; detekcja koloru pojazdy; rzeczywiste dane o ruchu drogowym;

\section{REFERENCES}

[1] Du S, Ibrahim M, Shehata MS, Badawy WM. Automatic license plate recognition (alpr): A state-of-theart review. IEEE Trans. Circuits Syst. Video Techn. 2013;23(2): 311-325.

[2] Wang F, Man L, Wang B, Xiao Y, Pan W, Lu X. Fuzzybased algorithm for colour recognition of license plates. Pattern Recognition Letters. 2008;29(7): 1007-1020.

[3] Bay H, Ess A, Tuytelaars T, Van Gool L. Speeded-up robust features (surf). Comput. Vis. Image Underst. 2008;110: 346-359.

[4] Pearce G, Pears N. Automatic make and model recognition from frontal images of cars. $8^{\text {th }}$ IEEE International Conference on Advanced Video and Signal-Based Surveillance (AVSS), 30 Aug.-2 Sept. 2011, Klagenfurt, Austria. IEEE; 2011. p. 373-378. 
[5] Gupta P, Purohit GN Saroj K. Vehicle color recognition system using CCTV cameras. International Journal of Advanced Research in Computer Science and Software Engineering. 2014;4(1): 383-389.

[6] Baran R, Glowacz A, Matiolanski A. The efficient realand non-real-time make and model recognition of cars. Multimedia Tools and Applications. 2015;74(12): 4269-4288.

[7] Gu H-Z, Lee S-Y. Car model recognition by utilizing symmetric property to overcome severe pose variation. Machine Vision and Applications. 2013;24(2): 255-274.

[8] Butzke M, Silva AG, Hounsell M, Pillon MA. Automatic recognition of vehicle attributes: color classification and logo segmentation. Hifen. 2008;32(62): 293-300.

[9] Chen Z, Pears N, Freeman M, Austin J. Road vehicle classification using support vector machines. IEEE International Conference on Intelligent Computing and Intelligent Systems, ICIS 2009, 20-22 Nov. 2009, Shanghai, China. IEEE; 2009. p. 214-218.

[10] Zhan W, Wan Q. Real-time and automatic vehicle type recognition system design and its application. In: $\mathrm{Li}$ Z, Li X, Liu Y, Cai Z. (eds.) Computational Intelligence and Intelligent Systems. Communications in Computer and Information Science, Vol. 316. Berlin, Heidelberg: Springer; 2012. p. 200-208.

[11] COST. TUD COST Action 323. Weighing in motion of road vehicles; 1999.

[12] Federal Highway Administration. Available from: http://www.fhwa.dot.gov.

[13] Negri P, Clady X, Milgram M, Poulenard R. An oriented-contour point based voting algorithm for vehicle type classification. $18^{\text {th }}$ International Conference on Pattern Recognition, ICPR 2006, 20-24 Aug. 2006, Hong Kong, China. IEEE; 2006. p. 574-577.

[14] Munroe DT, Madden MG. Multi-class and single-class classification approaches to vehicle model recognition from images. AICS; 2005.

[15] Petrovic V, Cootes TF. Analysis of features for rigid structure vehicle type recognition. British Machine Vision Conference, 7-9 Sep. 2004, London, U.K.; 2004. p. 587-596.

[16] Kazemi FM, Samadi S, Poorreza HR, Akbarzadeh-Totonchi MR. Vehicle recognition using curvelet transform and SVM. Forth International Conference on Information Technology, ITNG'07, 2-4 Apr. 2007, Las Vegas, NV, USA. IEEE; 2007. p. 516-521.

[17] Iqbal U, Zamir SW, Shahid MH, Parwaiz K, Yasin M, Sarfraz M. Image based vehicle type identification. 2010 International Conference on Information and Emerging Technologies (ICIET), 14-16 June 2010, Harachi, Pakistan. IEEE; 2010. p. 1-5.

[18] Vapnik VN. The nature of statistical learning theory. New York: Springer-Verlag; 1995.

[19] Bernardo JM, Smith AFM. Bayesian Theory. John Wiley \& Sons; 2008. p. 587-595.

[20] Lee H. Neural network approach to identify model of vehicles. In: Wang J, Yi Z, Zurada JM, Lu BL, Yin H. (eds.) Advances in Neural Networks - ISNN 2006. Lecture Notes in Computer Science, Vol. 3973. Berlin,
Heidelberg: Springer; 2006. p. 66-72

[21] Abdelmaseeh M, Badreldin I, Abdelkader M, El Saban M. Car make and model recognition combining global and local cues. $21^{\text {st }}$ International Conference on Pattern Recognition (ICPR 2012), 11-15 Nov. 2012, Tsukuba, Japan; 2012. p. 910-913.

[22] Wu Y-T, Kao J-H, Shih M-Y. A vehicle color classification method for video surveillance system concerning model-based background subtraction. Proceedings of the $11^{\text {th }}$ Pacific Rim Conference on Multimedia: Advances in Multimedia Information Processing - PCM 2010, 21-24 Sep. 2010, Shanghai, China; 2010. p. 369-380.

[23] Baek N, Park S-M, Kim K-J, Park S-B. Vehicle color classification based on the support vector machine method. In: Huang DS, Heutte L, Loog M. (eds.) Advanced Intelligent Computing Theories and Applications. With Aspects of Contemporary Intelligent Computing Techniques. ICIC 2007, Communications in Computer and Information Science, vol. 2; Berlin, Heidelberg: Springer; 2007. p. 1133-1139.

[24] Kim K-J, Park S-M, Choi Y-J. Deciding the number of color histogram bins for vehicle color recognition. IEEE Asia-Pacific Services Computing Conference (APSCC '08), 9-12 Dec. 2008, Yilan, Taiwan. IEEE; 2008. p. 134-138.

[25] Son J-W, Park S-B, Kim K-J. A convolution kernel method for color recognition. Sixth International Conference on Advanced Language Processing and Web Information Technology (ALPIT 2007), 22-24 Aug. 2007, Luoyang, Henan, China. IEEE; 2007. p. 242-247.

[26] Badura P, Skotnicka M. Automatic car make recognition in low-quality images. In: Piętka E, Kawa J, Wieclawek W. (eds.) Information Technologies in Biomedicine, Volume 3. Advances in Intelligent Systems and Computing, vol. 283. Cham, Switzerland: Springer; 2014. p. 235-246.

[27] Wieclawek W, Pietka E. Car Segmentation and Color Recognition. Proceedings of the $21^{\text {st }}$ International Conference: Mixed Design of Integrated Circuits Systems (MIXDES), 19-21 June 2014, Lublin, Poland. IEEE; 2014. p. 426-429.

[28] Lowe DG. Object recognition from local scale-invariant features. The Proceedings of the Seventh IEEE International Conference on Computer Vision, 20-27 Sep. 1999, Kerkyra, Greece. IEEE; 1999. p. 1150-1157.

[29] Lowe DG. Distinctive image features from scale-invariant keypoints. Int. J. Comput. Vision. 2004;60: 91-110.

[30] Lindeberg T. Scale-space theory: A basic tool for analysing structures at differentscales. Journal of Applied Statistics. 1994; 21(2):224-270.

[31] Lindeberg T. Scale-Space Theory in Computer Vision. Norwell: Kluwer Academic Publishers; 1994.

[32] Badura S, Foltan S. Advanced scale-space, invariant, low detailed feature recognition from images - car brand recognition. Proceedings of the 2010 International Multiconference on Computer Science and Information Technology (IMCSIT), 18-20 Oct 2010, Wisla, Poland. IEEE; 2010. p. 19-23. 